\section{Vaping in Medicine: A Review of Vaping Associated Lung Pathology}

\author{
Nicole Marie Sakla ${ }^{1 *}$ Thomas James Stavola ${ }^{2}$, Peter John \\ Wawrzusin $^{3}$ and Michael Sadler ${ }^{1}$ \\ ${ }^{1}$ Newark Beth Israel Medical Center, Newark, NJ, USA \\ ${ }^{2}$ Philadelphia College of Osteopathic Medicine, Philadelphia, PA, USA \\ ${ }^{3}$ Rutgers New Jersey Medical School, Newark, NJ, USA
}

\begin{abstract}
Vaping is a new development within the field of radiology and medicine at large with respect to the development of Acute Respiratory Distress Syndrome (ARDS) from Tetrahydrocannabinol (THC) containing Electronic Nicotine Delivery Systems (ENDS). Similar to the initial marketing of cigarettes, vaping was advertized as being a safe product with limited ingredients. ENDS products were eventually touted as being superior to cigarettes because of the aforementioned limited ingredients compared to the numerous carcinogenic elements found in cigarettes. The four typical constituents are propylene glycol, vegetable glycerin, nicotine, and a flavorant. The variety of flavors is particularly marketable towards the youth and within the past year, an increasing volume of patients have been admitted secondary to respiratory symptoms associated with vaping. Four computed tomography (CT) patterns of vaping induced lung injury have been identified and include acute eosinophilic pneumonia, diffuse alveolar damage, organizing pneumonia and lipoid pneumonia. The field of radiology has therefore been at the forefront of disease recognition with the goal of initiating treatment expeditiously in those with lung pathology caused by a product that was initially marketed as a safe alternative to cigarette smoking.
\end{abstract}

\section{Commentary}

ARDS is a lung pathology associated with numerous etiologies $[1,2]$. When discussed in the setting of vaping, a chemical induced lung injury is responsible for the subsequent lung pathology and eventual hypoxia experienced by the patient [3]. ARDS is the feared

*Corresponding author: Nicole Marie Sakla, Newark Beth Israel Medical Center, Newark, NJ, USA, Tel: +1 3017932898; E-mail: nsakla4813@gmail.com

Citation: Sakla NM, Stavola TJ, Wawrzusin PJ, Sadler M (2020) Vaping in Medicine: A Review of Vaping Associated Lung Pathology. J Addict Addictv Disord 7: 44.

Received: June 08, 2020; Accepted: June 15, 2020; Published: June 24, 2020

Copyright: (c) 2020 Sakla NM, et al. This is an open-access article distributed under the terms of the Creative Commons Attribution License, which permits unrestricted use, distribution, and reproduction in any medium, provided the original author and source are credited. complication of vaping use and is typically diagnosed in otherwise healthy individuals [4,5]. Medically, ARDS is diagnosed when hypoxia, alveolar destruction and hypercapnia occur simultaneously as a result of severe lung injury [1,2,4-9]. The role of imaging was therefore considered a supportive tool rather than diagnostic as long as the patient met the aforementioned physical exam criteria [8]. With advances in the field of radiology however, CT examinations can identify and prognosticate lung injury caused by vaping in the appropriate clinical setting $[4,5,8]$.

Currently, there are four CT lung injury patterns classically associated with vaping [3-5]. These include acute eosinophilic pneumonia, diffuse alveolar damage, organizing pneumonia and lipoid pneumonia [3-5]. The inciting chemical injury propagated by vaping products is likely secondary to various vitamin E derivatives often found in these THC containing products [3]. All forms of vaping induced lung injury are associated with the provocation of a pulmonary inflammatory response that ultimately results in alveolar destruction through variable mechanisms thereafter $[3-5,10,11]$.

Eosinophilic pneumonia is one of the lung injury mechanisms associated with vaping. Typically, eosinophilic pneumonia will manifest as scattered areas of groundglass opacification and pleural effusions on CT with associated eosinophilia [3-5]. Similarly, diffuse alveolar damage is also associated with disseminated groundglass opacification but progresses towards basilar predominant honeycombing and fibrosis [2-5,8,12-14]. Organizing pneumonia is unique in that it is associated with sporadic and migratory CT findings which may include subpleural and peribronchovascular opacification [3-5]. The migratory findings of organizing pneumonia are not typically seen in eosinophilic pneumonia or diffuse alveolar damage [3-5]. Lastly, lipoid pneumonia manifests as dependent consolidations within the lung parenchyma that occur secondary to fat or oil induced damage [3-5].

The role of imaging in the detection of vaping associated lung pathology is growing with increased emphasis on image findings [3$5,14]$. CT enables radiologists to uncover components of a patient's medical history that are not classically considered a cause for the severe respiratory symptoms associated with ARDS [3-5,14]. Through early identification, respiratory support and monitoring can be initiated without delay $[4,5]$. When dependent opacities are visualized on the CT examinations of young and otherwise healthy patients, vaping should be considered as a differential $[4,5,14]$. ARDS classically presents in an early and late phase [3-5,14]. The early phase is characterized by bibasilar dependent lung changes $[4,5,14]$. The late phase is more variable and may depict nondependent changes [4,5,14].

\section{Conclusion}

Overall, the increased use of ENDS products is primarily seen amongst the youth and vaping associated lung injury should be considered as a differential when young patients present with severe respiratory symptoms in the appropriate clinical setting [3-5,15-17]. 
A thorough substance use history should be obtained from all patients upon admission to the hospital; however direct questioning with respect to vaping products may need to be elicited because of the commonly dissociated perception of vaping as a type of drug use. With the identification and diagnosis of vaping associated ARDS, it is the hope that early medical intervention can be initiated, with subsequent psychosocial support provided for patients who struggle to quit vaping. This article proposes that the early identification of vaping induced lung pathology is paramount in the treatment of ARDS and that the prevention of such severe pulmonary disease is accomplished in part through pre-emptive patient education.

\section{Conflict of Interest}

The authors declare that they have no conflict of interest.

\section{References}

1. Bellingan GJ (2002) The pulmonary physician in critical care * 6: The pathogenesis of ALI/ARDS. Thorax 57: 540-546.

2. Bouros D, Nicholson A, Polychronopoulos V, Bois RD (2000) Acute interstitial pneumonia. European Respiratory Journal 15: 412-418.

3. Christiani DC (2019) Vaping-induced lung injury. N Engl J Med 382: 960962.

4. Sakla NM, Gattu R, Singh G, Sadler M (2020) Vaping-associated acute respiratory distress syndrome. Emergency Radiology 27: 103-106.

5. Sakla NM, Wawrzusin PJ, Sadler SR, Sadler M (2020) Vaping and acute respiratory distress syndrome in interventional radiology. Journal of Imaging and Interventional Radiology 3: 1-2.

6. Gattinoni L, Quintel M (2016) Fifty years of research in ARDS why is acute respiratory distress syndrome so important for critical care? American Journal of Respiratory and Critical Care Medicine 194: 1051-1052.

7. Hopkins RO, Weaver LK, Orme JF, Chan KJ (2005) Two-year cognitive, emotional, and quality-of-life outcomes in acute respiratory distress syndrome. American Journal of Respiratory and Critical Care Medicine 172: 786-787.
8. Pierrakos C, Karanikolas M, Scolletta S, Karamouzos V, Velissaris D (2012) Acute respiratory distress syndrome: Pathophysiology and therapeutic options. J Clin Med Res 4: 7-16.

9. Rawal G, Yadav S, Kumar R (2018) Acute respiratory distress syndrome: An update and review. J Transl Int Med 6: 74-77.

10. Flower M, Nandakumar L, Singh M, Wyld D, Windsor M, et al., (2017) Respiratory bronchiolitis-associated interstitial lung disease secondary to electronic nicotine delivery system use confirmed with open lung biopsy. Respirology Case Reports 5: 00230.

11. Lerner CA, Sundar IK, Yao H, Gerloff J, Ossip DJ, et al. (2015) Vapors produced by electronic cigarettes and E-Juices with flavorings induce toxicity, oxidative stress, and inflammatory response in lung epithelial cells and in mouse lung. Plos One 10: 0116732.

12. Sharp C, Millar AB, Medford AR (2015) Advances in understanding of the pathogenesis of acute respiratory distress syndrome. Respiration 89 : $420-434$

13. Talhout R, Schulz T, Florek E, Benthem JV, Wester P, et al. (2011) Hazardous compounds in tobacco smoke. Int J Environ Res Public Health 8: 613-628.

14. Zompatori M, Ciccarese F, Fasano L (2014) Overview of current lung imaging in acute respiratory distress syndrome. Eur Respir Rev 23: 519-530.

15. Centor RM, Rigotti NA (2019) Annals on call-weighing the potential benefits and harms of e-cigarettes. Ann Intern Med 170

16. Lloyd SL, Striley CW (2018) Marijuana use among adults 50 years or older in the 21st century. Gerontology and Geriatric Medicine 4: 1-14.

17. Lestari KS, Humairo MV, Agustina U (2018) Formaldehyde vapor concentration in electronic cigarettes and health complaints of electronic cigarettes smokers in Indonesia. Journal of Environmental and Public Health $1-6$. 


\section{If}

Advances In Industrial Biotechnology | ISSN: 2639-5665

Advances In Microbiology Research | ISSN: 2689-694X

Archives Of Surgery And Surgical Education | ISSN: 2689-3126

Archives Of Urology

Archives Of Zoological Studies | ISSN: 2640-7779

Current Trends Medical And Biological Engineering

International Journal Of Case Reports And Therapeutic Studies | ISSN: 2689-310X

Journal Of Addiction \& Addictive Disorders | ISSN: 2578-7276

Journal Of Agronomy \& Agricultural Science | ISSN: 2689-8292

Journal Of AIDS Clinical Research \& STDs | ISSN: 2572-7370

Journal Of Alcoholism Drug Abuse \& Substance Dependence | ISSN: 2572-9594

Journal Of Allergy Disorders \& Therapy | ISSN: 2470-749X

Journal Of Alternative Complementary \& Integrative Medicine | ISSN: 2470-7562

Journal Of Alzheimers \& Neurodegenerative Diseases | ISSN: 2572-9608

Journal Of Anesthesia \& Clinical Care | ISSN: 2378-8879

Journal Of Angiology \& Vascular Surgery | ISSN: 2572-7397

Journal Of Animal Research \& Veterinary Science | ISSN: 2639-3751

Journal Of Aquaculture \& Fisheries | ISSN: 2576-5523

Journal Of Atmospheric \& Earth Sciences | ISSN: 2689-8780

Journal Of Biotech Research \& Biochemistry

Journal Of Brain \& Neuroscience Research

Journal Of Cancer Biology \& Treatment | ISSN: 2470-7546

Journal Of Cardiology Study \& Research | ISSN: 2640-768X

Journal Of Cell Biology \& Cell Metabolism | ISSN: 2381-1943

Journal Of Clinical Dermatology \& Therapy | ISSN: 2378-8771

Journal Of Clinical Immunology \& Immunotherapy | ISSN: 2378-8844

Journal Of Clinical Studies \& Medical Case Reports | ISSN: 2378-8801

Journal Of Community Medicine \& Public Health Care | ISSN: 2381-1978

Journal Of Cytology \& Tissue Biology | ISSN: 2378-9107

Journal Of Dairy Research \& Technology | ISSN: 2688-9315

Journal Of Dentistry Oral Health \& Cosmesis | ISSN: 2473-6783

Journal Of Diabetes \& Metabolic Disorders | ISSN: 2381-201X

Journal Of Emergency Medicine Trauma \& Surgical Care | ISSN: 2378-8798

Journal Of Environmental Science Current Research | ISSN: 2643-5020

Journal Of Food Science \& Nutrition | ISSN: 2470-1076

Journal Of Forensic Legal \& Investigative Sciences | ISSN: 2473-733X

Journal Of Gastroenterology \& Hepatology Research | ISSN: 2574-2566
Journal Of Genetics \& Genomic Sciences | ISSN: 2574-2485

Journal Of Gerontology \& Geriatric Medicine | ISSN: 2381-8662

Journal Of Hematology Blood Transfusion \& Disorders | ISSN: 2572-2999

Journal Of Hospice \& Palliative Medical Care

Journal Of Human Endocrinology | ISSN: 2572-9640

Journal Of Infectious \& Non Infectious Diseases | ISSN: 2381-8654

Journal Of Internal Medicine \& Primary Healthcare | ISSN: 2574-2493

Journal Of Light \& Laser Current Trends

Journal Of Medicine Study \& Research | ISSN: 2639-5657

Journal Of Modern Chemical Sciences

Journal Of Nanotechnology Nanomedicine \& Nanobiotechnology | ISSN: 2381-2044

Journal Of Neonatology \& Clinical Pediatrics | ISSN: 2378-878X

Journal Of Nephrology \& Renal Therapy | ISSN: 2473-7313

Journal Of Non Invasive Vascular Investigation | ISSN: 2572-7400

Journal Of Nuclear Medicine Radiology \& Radiation Therapy | ISSN: 2572-7419

Journal Of Obesity \& Weight Loss | ISSN: 2473-7372

Journal Of Ophthalmology \& Clinical Research | ISSN: 2378-8887

Journal Of Orthopedic Research \& Physiotherapy | ISSN: 2381-2052

Journal Of Otolaryngology Head \& Neck Surgery | ISSN: 2573-010X

Journal Of Pathology Clinical \& Medical Research

Journal Of Pharmacology Pharmaceutics \& Pharmacovigilance | ISSN: 2639-5649

Journal Of Physical Medicine Rehabilitation \& Disabilities | ISSN: 2381-8670

Journal Of Plant Science Current Research | ISSN: 2639-3743

Journal Of Practical \& Professional Nursing | ISSN: 2639-5681

Journal Of Protein Research \& Bioinformatics

Journal Of Psychiatry Depression \& Anxiety | ISSN: 2573-0150

Journal Of Pulmonary Medicine \& Respiratory Research | ISSN: 2573-0177

Journal Of Reproductive Medicine Gynaecology \& Obstetrics | ISSN: 2574-2574

Journal Of Stem Cells Research Development \& Therapy | ISSN: 2381-2060

Journal Of Surgery Current Trends \& Innovations | ISSN: 2578-7284

Journal Of Toxicology Current Research | ISSN: 2639-3735

Journal Of Translational Science And Research

Journal Of Vaccines Research \& Vaccination | ISSN: 2573-0193

Journal Of Virology \& Antivirals

Sports Medicine And Injury Care Journal | ISSN: 2689-8829

Trends In Anatomy \& Physiology | ISSN: 2640-7752

Submit Your Manuscript: https://www.heraldopenaccess.us/submit-manuscript 